\title{
Adipose mesenchymal stem cells and gingival mesenchymal stem cells have a comparable effect in endothelium repair
}

\author{
$\mathrm{KE} \mathrm{YANG}^{1 *}$, DONGMEI XIE ${ }^{1 *}$, WANWEN LIN ${ }^{1}$, PENG XIANG $^{2}$ and CHAOQUAN PENG ${ }^{1}$ \\ ${ }^{1}$ Department of Cardiology, The Third Affiliated Hospital of Sun Yat-sen University, Guangzhou, Guangdong 510630; \\ ${ }^{2}$ Key Laboratory for Stem Cells and Tissue Engineering, Center for Stem Cell Biology and Tissue Engineering, \\ Ministry of Education, Sun Yat-sen University, Guangzhou, Guangdong 510600, P.R. China
}

Received November 8, 2020; Accepted July 14, 2021

DOI: $10.3892 /$ etm.2021.10851

\begin{abstract}
Restenosis is the major factor influencing the long-term success rate of angioplasty and stent implantation and effective strategies to prevent restenosis remain limited. Mesenchymal stem cells (MSCs) are pluripotent stem cells capable of self-renewal and multidirectional differentiation, which may be able to promote endothelium repair, thereby reducing restenosis. The present study aimed to evaluate the effects of adipose MSCs (AMSCs) and gingival MSCs (GMSCs) on endothelium repair. MSCs were isolated from two human tissue types, namely adipose tissue and gingival tissue, and the effects of AMSCs and GMSCs in ex vivo endothelium repair and on vascular smooth muscle cell (SMC) growth were examined. To compare the feasibility of using AMSCs and GMSCs for the repair of endothelium damage in endothelial cell (EC) damage and vasoproliferative disorders, an ex vivo model of endothelium repair in a co-culture system was developed. It was indicated that AMSCs and GMSCs expressed characteristic MSC markers (CD105 and CD166). 3H-thymidine incorporation in the co-culture group of AMSCs and SMCs in the presence of ECs was lower compared with that in the GMSC and SMC co-culture group. The protein expression level of proliferating cell nuclear antigen in the co-culture group of AMSCs and SMCs in the presence of ECs were lower compared with that in the GMSC and SMC co-culture group. After co-culture with ECs for 5 days, 25.71 $\pm 3.08 \%$ of AMSCs began to express CD31 protein and 20.06 $\pm 2.09 \%$ of GMSCs began to express CD31 protein. Furthermore, anti-VEGF antibody was able to inhibit MSC differentiation. Collectively,
\end{abstract}

Correspondence to: $\mathrm{Dr}$ Chaoquan Peng, Department of Cardiology, The Third Affiliated Hospital of Sun Yat-sen University, 3rd Floor of Complex Building, 600 Tianhe Road, Guangzhou, Guangdong 510630, P.R. China

E-mail: seegeryoung@163.com

${ }^{*}$ Contributed equally

Key words: mesenchymal stem cells, endothelium repair, vascular smooth muscle cell the present results suggested that seeding of AMSCs had a stronger effect to inhibit the proliferation and migration of SMCs compared with GMSCs.

\section{Introduction}

Myocardial infarction is the leading cause of cardiovascular death and percutaneous coronary intervention (PCI) treatment is currently the major treatment. However, PCI treatment has its limitations. Among them, in-stent restenosis (ISR) and thrombosis after PCI are problems that have not yet been resolved. During the surgical operation, the balloon or stent implanted in the blood vessel may directly cause damage to the vascular intima. When the stent expands, it directly squeezes the vascular intima $(1,2)$, resulting in denudation of endothelial cells (ECs), exposure of the subendothelial matrix and direct promotion of the inflammatory response that hinders endothelial repair. Thus, it is of great significance to investigate methods and mechanisms that promote the repair of vascular ECs.

Accelerating intact endothelium repair with stem cell transplantation has been proposed as a novel method for restenosis prevention. Mesenchymal stem cells (MSCs) are pluripotent stem cells with self-renewal and multidirectional differentiation abilities, which are derived from the mesoderm and ectoderm in early development (3-7). Accumulating evidence suggests that the peak of EC regeneration parallels with the peak of smooth muscle cell (SMC) proliferation and that the growth-stimulating cytokines secreted by proliferative ECs are also upregulated $(8,9)$. Stem cells may promote EC repair by secreting factors such as $\mathrm{C}-\mathrm{C}$ motif chemokine ligand 5 (CCL5), vascular endothelial growth factor (VEGF) and fibroblast growth factor (FGF) that promote angiogenesis.

Adipose MSCs (AMSCs) have the characteristics of abundant autologous sources, convenient acquisition of materials, avoiding immune rejection and multidirectional differentiation ability, and have become a novel hot spot in seed cell research. In a mouse model of chronic graft-versus-host disease, it has been revealed that gingival MSCs (GMSCs) have a stronger immunomodulatory function compared with AMSCs. Furthermore, similar to other types of MSC, GMSCs have anti-inflammatory and immune regulatory functions. 
Therefore, it was hypothesized that MSCs may reduce restenosis by promoting endothelium repair. In the present study, a comparison of the effects of AMSCs and GMSCs on the proliferation and migration of SMCs, as well as the plasticity of the seeded AMSCs and GMSCs towards the endothelial lineage, was performed.

\section{Materials and methods}

Animals. A total of 16 male and 8 female healthy New Zealand rabbits (age, 3 months; bodyweight, 2.0-2.5 kg purchased from the Huadong Xinhua experimental animal farm of Guangzhou were kept under constant housing conditions (temperature, $16-26^{\circ} \mathrm{C}$; relative humidity, $40-70 \% ; 12 \mathrm{~h}$ light/dark cycle; each time the experimental rabbits were provided with $\sim 50 \mathrm{~g}$ of feed, continuous supply of drinking water was assured). Male rabbits and female rabbits were bred to give birth to newborn rabbits, whichwere used to extract ECs. The umbilical cords of newborn rabbits were used to extract ECs. The animal experimental protocol, as well as care for the animals, conformed to the principles of animal ethics and the relevant regulations of the national laboratory animal ethics and welfare ethics issued by Chinese National Institute of Health and was reviewed and approved by the Experimental Animal Ethics Committee of The Third Affiliated Hospital of Sun Yat-sen University. The rabbits were first anesthetized with $0.3 \%$ pentobarbital $(30 \mathrm{mg} / \mathrm{kg})$ via the ear vein and then SMCs were collected. ECs were isolated from newborn rabbit umbilical cords. After the tissues were collected, the rabbits were euthanized with $0.3 \%$ pentobarbital sodium $(100 \mathrm{mg} / \mathrm{kg})$ via ear vein injection.

After the tissues were obtained, the rabbits were euthanized with $0.3 \%$ pentobarbital sodium $(100 \mathrm{mg} / \mathrm{kg})$ by ear vein injection. The numbers of animals used and euthanized are 24 adult rabbits and 20 newborn rabbits. Death was confirmed by the absence of heartbeat and spontaneous breathing for $1 \mathrm{~h}$.

Primary culture of rabbit ECs. ECs were enzymatically isolated from 20 newborn rabbit umbilical cords at 4 months of gestation and cultured as previously described (10). The umbilical cord of newborn rabbits was washed repeatedly with PBS under sterile conditions until the liquid was clear. Cells were digested at room temperature for 20-30 min with $0.1 \%$ collagenase type I (Guangzhou Scissor Hand Gene Technology Co., Ltd.). The resulting suspension was collected and centrifuged for $7 \mathrm{~min}$ at $800 \mathrm{x} \mathrm{g}$ at $4^{\circ} \mathrm{C}$. Subsequently, the supernatant was discarded. Complete medium [60\% M199; 20\% serum-free medium (EBM Endothelial Cell Basal Medium); 20\% FBS; 2 mmol/1 glutamine; and $60 \mathrm{mg} / \mathrm{l}$ endothelial cell growth supplement; all from ScienCell Research Laboratories, Inc.] was preheated and used to suspend the cells, which were cultured in flasks after pipetting and mixing. The cells were cultured in an incubator at $37^{\circ} \mathrm{C}$ with $5 \% \mathrm{CO}_{2}$ and saturated humidity. After $48 \mathrm{~h}$, the medium was replaced, and thereafter, it was replaced every 2-3 days. In total, $>95 \%$ of cells were positive on immunohistochemical staining with antibody against von Willebrand factor (vWF)-related antigen (1:500; cat. no. ab216566; Abcam).
Primary culture of rabbit SMCs. SMCs were obtained from the adult rabbit aorta using the explant method (11). At total of 24 rabbits were anesthetized with $0.3 \%$ pentobarbital (30 mg/kg) via the ear vein and SMCs were then collected. After the tissues were taken, the rabbits were euthanized with $0.3 \%$ pentobarbital sodium $(100 \mathrm{mg} / \mathrm{kg})$ ear vein injection. Ophthalmic scissors were used to cut longitudinally from one end of the thoracic aorta to expose the endodermis. The endothelium was removed by pinching and scraping it with an elbow ophthalmic instrument. The fibroblasts and ECs were fully washed twice in fresh medium. The cells of passages 3-5 were used for experiments. The cells cultured using this method contained $\geq 95 \%$ SMCs, which were confirmed by positive staining with the antibody against $\alpha$-smooth muscle actin ( $\alpha$-SMA) (1:500; cat. no. ab244177; Abcam).

Isolation and culture of human AMSCs and GMSCs. Regarding the use of samples from patients, the experimental protocol of the present study was reviewed and approved by the Medical Ethics Committee of the Third Affiliated Hospital of Sun Yat-Sen University (Guangzhou, China). Furthermore, all patients provided written informed consent. The total number of patients was 40, 20 of which provided adipose tissue and the other 20 provided gingival tissue (Age range, 18-40-years old). Both males and females were included. The location of the donation organization was The Third Affiliated Hospital of Sun Yat-sen University (Guangzhou, China) and the samples were collected from August 2019 to May 2020. The procedure was in accordance with a previous protocol (5). After plastic surgery, discarded human neck adipose tissue was cleaned three times with PBS. The adipose tissue was cut into small pieces $\sim 1-\mathrm{mm}^{3}$ in size with tissue scissors. Subsequently, the tissue was digested in a water bath at $37^{\circ} \mathrm{C}$ for 30 min with $0.1 \%$ collagenase I (Guangzhou Scissor Hand Gene Technology Co., Ltd.) and placed in a centrifuge. After centrifugation for $5 \mathrm{~min}$ at $800 \mathrm{x} \mathrm{g}$ at $4^{\circ} \mathrm{C}$, the cells were collected and resuspended with an appropriate amount of PBS. The cells were placed in an incubator with saturated humidity and $5 \% \mathrm{CO}_{2}$ at $37^{\circ} \mathrm{C}$ cultured with $\alpha$-MEM medium (HyClone; Cytiva).

Gingival tissue was obtained via orthodontic tooth extraction (informed consent from the donors was provided). The procedure was in accordance with a previous protocol (12). The gingival tissue was cut into small pieces $\sim 1-\mathrm{mm}^{3}$ in size with tissue scissors. Subsequently, the tissue was digested in a water bath at $37^{\circ} \mathrm{C}$ for $1 \mathrm{~h}$ with $0.1 \%$ collagenase I and placed in a centrifuge. After centrifugation for $5 \mathrm{~min}$ at $800 \mathrm{xg}$ at $4^{\circ} \mathrm{C}$, the cells were collected and resuspended with an appropriate amount of PBS. The cells were placed in an incubator with saturated humidity and $5 \% \mathrm{CO}_{2}$ at $37^{\circ} \mathrm{C}$ cultured with $\alpha$-MEM medium (HyClone; Cytiva).

EC-conditioned medium. Rabbit ECs were cultured in DMEM (Gibco; Thermo Fisher Scientific, Inc.) supplemented with $10 \%$ FBS (HyClone; Cytiva) in 6-well plates. When cells grew to $\sim 60 \%$ confluence, the medium was changed to fresh serum-free DMEM. After the cells were incubated for another $24 \mathrm{~h}$, the conditioned medium was collected, centrifuged at $15,000 \mathrm{x} \mathrm{g}$ for $3 \mathrm{~min}$ at $4^{\circ} \mathrm{C}$ and filtered through $0.22-\mu \mathrm{m}$ filters. 
Fluorescence-assisted cell sorting (FACS) analysis. To study the effect of VEGF or EC-conditioned medium on AMSC and GMSC differentiation, AMSCs and GMSCs were cultured in 24-well plates covered with circular glass slides. When AMSCs and bone marrow stromal cells (BMSCs) grew to $\sim 60 \%$ confluence, the medium was replaced with a DMEM containing $50 \mathrm{ng} / \mathrm{ml} \mathrm{VEGF}$ or EC-conditioned medium. When ECs grew to $60 \%$, AMSCs and BMSCs were seeded on ECs. After $6 \mathrm{~h}$, the non-adherent AMSCs and BMSCs were removed. AMSCs and BMSCs were cultured in DMEM containing VEGF, EC-conditioned medium or co-cultured with ECs for 5 days. Human AMSCs and GMSCs of the third generation in the above groups were digested with trypsin to prepare a single-cell suspension. The cells were centrifuged for $5 \mathrm{~min}$ at $800 \mathrm{x} \mathrm{g}$ at $4^{\circ} \mathrm{C}$ and the supernatant was discarded. The cells were suspended with PBS for counting. The cell concentration was adjusted to $1 \times 10^{7} / \mathrm{ml}$ and the suspension was aliquoted into new tubes. The following antibodies were added: CD105 (cat. no. ab184667; Abcam), CD166 (cat. no. ab219139; Abcam), CD34 (cat. no. ab223930; Abcam), CD31 (cat. no. ab33858; Abcam) and vWF (cat. no. ab195028; Abcam). The amount of antibody used was according to the manufacturer's protocol. The cells were mixed and incubated at $4^{\circ} \mathrm{C}$ for $30 \mathrm{~min}$. PBS was used to wash cells twice to remove any unbound flow antibody. The expression levels of various markers were detected using $300 \mu \mathrm{l}$ PBS following resuspension.

In vitro differentiation experiment of AMSCs and GMSCs Osteogenic differentiation. When the third-generation AMSCs and GMSCs grew to a density of $65-75 \%$, the osteogenic differentiation culture medium (L-DMEM medium added with $100 \mathrm{nM}$ dexamethasone; $0.2 \mathrm{mM}$ triose $\mathrm{C} ; 10 \mathrm{mM} \beta$-glycerol low sodium, $10 \%$ fetal bovine dispersion; and $1 \%$ penicillin/streptomycin; PanEra Biologicals; Panera Laboratories, Inc.) was changed. The normal medium was changed to differentiation medium for 10-14 days. After 10 days of induced differentiation, clusters of cells with calcium nodules appeared. Alizarin Red S staining solution was added for staining. The cells were washed with PBS three times and then fixed with $95 \%$ alcohol for $15 \mathrm{~min}$ at room temperature. They were stained with $1 \%$ Alizarin Red (0.1 g Alizarin Red added to $100 \mathrm{ml}$ of $0.1 \mathrm{M}$ Tris- $\mathrm{HCl}$ ) for $5 \mathrm{~min}$ in room temperature and washed with PBS again.

Adipogenic differentiation. After the cell density reached 90\%, adipogenic differentiation medium (High DMEM medium added with $10 \%$ fetal bovine serum, $10 \mu \mathrm{g} / \mathrm{ml}$ insulin, $1 \mu \mathrm{M}$ dexamethasone, $0.5 \mathrm{mM}$ IBMX, $2 \mathrm{mM}$ indomethacin, and penicillin/streptomycin) (PanEra Biologicals; Panera Laboratories, Inc.) was changed. The normal medium was changed to differentiation medium for 10-14 days. At two weeks after the induction of differentiation, round and transparent fat droplets were visible under the microscope. Subsequently, Oil Red O staining solution was added for staining. The cells were washed with PBS three times, and stained with oil red $\mathrm{O}$ staining solution (oil red $\mathrm{O} 0.5 \mathrm{~g}$ added to $50 \%$ ethanol $100 \mathrm{ml}$ ) for $10-15 \mathrm{~min}$ in the dark at room temperature. Ethanol (50\%) was added for differentiation. Distilled water was used to terminate differentiation.
Chondrogenic differentiation. The concentration was adjusted to $1 \times 10^{6}$ cells $/ \mathrm{ml}$ and cells were inoculated in a 96-well plate at $200 \mu \mathrm{l} /$ well. After the cells were digested, they were seeded in the wells. Cartilage induction culture medium (High DMEM medium added with $10 \mathrm{ng} / \mathrm{ml}$ TGF- $\beta$; $50 \mathrm{mg} / \mathrm{ml} \mathrm{ITS;} 100 \mathrm{nM}$ dexamethasone; $50 \mu \mathrm{g} / \mathrm{ml}$ vitamin $\mathrm{C} ; 1 \mathrm{mM}$ sodium pyruvate; $40 \mu \mathrm{g} / \mathrm{ml}$ proline; and $1 \%$ penicillin/streptomycin; PanEra Biologicals; Panera Laboratories, Inc.) was added to the cell pellet. After 3 weeks, visible cell micelles were observed, which were subjected to Aniline Blue staining. The cells were fixed with $40 \mathrm{~g} / \mathrm{l}$ paraformaldehyde for $30 \mathrm{~min}$ at room temperature, then washed with PBS. They were immersed in $0.1 \%$ toluidine blue solution for $20 \mathrm{~min}$ at room temperature and then washed with distilled water. After decolorization in $0.5 \%$ hydrochloric acid solution for 2.0-3.0 sec, the cells were dehydrated using graded ethanol and vitrificated using xylene.

Co-culture protocol. The co-culture system was established as follows: ECs were inoculated in 6-well plates with DMEM supplemented with $10 \%$ FBS, and SMCs were inoculated in the upper chambers with DMEM supplemented with 10\% FBS of a Transwell insert (Corning Life Sciences; 8.0- $\mu \mathrm{m}$ ). AMSCs and BMSCs were implanted into the ECs layer (the cells reached $100 \%$ confluency) or were in the logarithmic growth phase (60\% confluency). After $6 \mathrm{~h}$, the non-adherent AMSCs and BMSCs were discarded and the medium was replaced with fresh serum-free DMEM. After $24 \mathrm{~h}$ of culture in serum-free DMEM, the Transwells were inserted into the assigned 6-well plates. According to the growth state/presence of the ECs and the proliferation of AMSCs and BMSCs, these were divided into five groups: i) Control group, no cells were present in the lower chamber; ii) ECs group, ECs reaching 100\% fusion were cultured in the lower compartment; iii) proliferative ECs group, ECs cultured in the lower compartment were in a state of proliferation; iv) AMSCs seed group, ECs and AMSCs co-cultured in the lower compartment were in a state of fusion growth; and v) GMSCs seed group, ECs and GMSCs co-cultured in lower compartment were in a state of fusion growth. After $24 \mathrm{~h}$ of cell co-culture, SMCs from the upper chamber were collected for examination of DNA synthesis and western blot analysis according to the protocol of the Transwell migration assay.

SMC DNA synthesis assay. DNA synthesis of SMCs was determined using the $3 \mathrm{H}$ thymine $(3 \mathrm{H}-\mathrm{TdR})$ method. The $3 \mathrm{H}-\mathrm{TdR}$ incorporation (final concentration, $37 \mathrm{kbq} / \mathrm{ml}$ ) co-culture system in the presence of ECs was employed (13). After $24 \mathrm{~h}$, the SMCs were collected and the radioactivity was determined with a liquid scintillation counter. The results are expressed as counts per min per well.

Western blot analysis. Total protein was extracted from cultured SMCs from each group using RIPA buffer (Beyotime Institute of Biotechnology) and quantified with a BCA Protein Assay kit (Beyotime Institute of Biotechnology). Equal amounts of protein were subjected to $10 \%$ SDS-PAGE and then transferred to polyvinylidene fluoride membranes (EMD Millipore). The mass of protein loaded per lane was $30 \mu \mathrm{g}$. After blocking with $5 \%$ non-fat milk (Biotium, Inc.) at room temperature for $1 \mathrm{~h}$, the membranes were incubated with primary antibodies against 

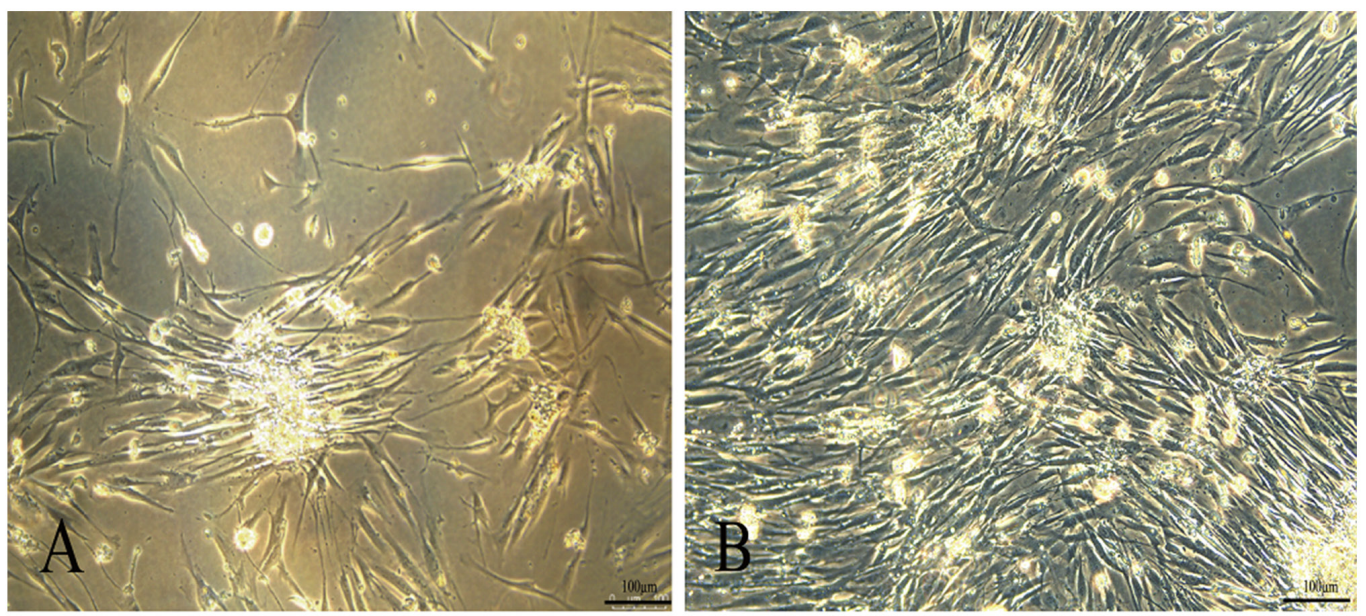

Figure 1. Morphological characterization of MSCs. (A) AMSCs and (B) GMSCs (magnification, x200; scale bar, $100 \mu \mathrm{m}$ ). MSCs, mesenchymal stem cells; AMSCs, adipose MSCs; GMSCs, gingival MSCs.

proliferating cell nuclear antigen (PCNA; dilution, 1:1,000; cat. no. 1311; Cell Signaling Technology, Inc.) and $\beta$-actin (dilution, 1:1,000; cat. no. 8457; Cell Signaling Technology, Inc.) at $4^{\circ} \mathrm{C}$ overnight, followed by probing with horseradish peroxidase-conjugated secondary antibody (dilution, 1:1,000; cat. no. 7074; Cell Signaling Technology, Inc.) for $2 \mathrm{~h}$ at room temperature. The immunoreactive bands were visualized using enhanced chemiluminescence (Thermo Fisher Scientific, Inc.) and semi-quantified with ImageJ software (National Institutes of Health, Bio-Rad Laboratories, Inc.; version 3.0.0.39296), with $\beta$-actin as an internal control.

Fluorescence immunocytochemistry. When ECs grew to $60 \%$, AMSCs and BMSCs were seeded on ECs. After $6 \mathrm{~h}$, the non-adherent AMSCs and BMSCs were removed. AMSCs and BMSCs co-cultured with ECs for 5 days. Different concentrations $(50,100,500 \mathrm{ng} / \mathrm{ml})$ of anti-VEGF antibody (cat.no.ab32152; Abcam) were added to the AMSCs and BMSCs co-cultured with ECs groups for 5 days. The cells were then washed with PBS, fixed with $4 \%$ paraformaldehyde for $15 \mathrm{~min}$ at room temperature and incubated with $0.5 \%$ Triton $\mathrm{X}-100$ at room temperature for $20 \mathrm{~min}$. Cells were blocked with $1 \%$ goat serum (Gibco; Thermo Fisher Scientific, Inc.) for $30 \mathrm{~min}$ at room temperature and then divided into four groups: CD31 (1:20; cat. no. ab9498), vWF (1:200; cat. no. ab154193), CD105 (1:500; cat. no. ab221675) and CD166 (1:90; cat. no. ab109215) (Abcam). Cells were incubated with the respective antibodies at $4^{\circ} \mathrm{C}$ overnight. Subsequently, the secondary fluorescent antibody goat anti-mouse IgG H\&L Alexa Fluor ${ }^{\circledR} 488$ (1:200; cat. no. ab150113; Abcam) and goat anti-mouse IgG H\&L Alexa Fluor+ 647 (1:200; cat. no. ab150115; Abcam) was added and samples were incubated at room temperature for $1 \mathrm{~h}$. Finally, DAPI was used to stain the nuclei for $5 \mathrm{~min}(1 \mathrm{mg} / \mathrm{ml})$ at room temperature. Cells were observed and images were captured under an inverted fluorescence microscope.

Statistical analysis. All of the data were processed using SPSS 16.0 software (SPSS, Inc.). Values are expressed as the mean \pm standard deviation. Multi-comparisons tests were performed using ANOVA with Bonferroni's post hoc test used for comparison between all of the groups. The difference was significant according to the test level of $\alpha=0.05$. $\mathrm{P}<0.05$ was considered to indicate a statistically significant difference.

\section{Results}

Phenotypic characterization and plasticity of AMSCs and GMSCs. At $24 \mathrm{~h}$ after inoculation, a small number of cells with fibroblast-like morphology cells began to scatter on the adherent surface of primary cultured human AMSCs. At $24 \mathrm{~h}$, most of the adherent cells were spindle-shaped fibroblast-like cells. The cells were further expanded and colonies of AMSCs of the third generation are presented in Fig. 1A.

Primary GMSCs slowly started to adhere at $4 \mathrm{~h}$ after inoculation. The nucleus of GMSCs was in the middle, the cell body was small and the shape was uniformly round or spindle-like. The third generation of GMSCs had a spindle-shaped fibroblast morphology. The cell colonies of the fifth generation were characterized by a central cluster of cells surrounded by radiating thin cells (Fig. 1B).

$v W F$ and CD31 expression levels in the differentiating MSCs. The phenotypic characterization of MSCs was performed via FACS. Compared with the negative controls, AMSCs did not express CD34, CD31 or vWF (Fig. 2A). CD34 is a surface marker of hematopoietic lineages, while CD31 and vWF are endothelial surface markers. AMSCs expressed characteristic MSC markers, including CD105 and CD166 (Fig. 2A). Compared with the negative controls, GMSCs did not express CD34, CD31 or vWF, which was the same observation as that for AMSCs (Fig. 2A). GMSCs expressed characteristic MSC markers, including CD73 and CD90. These results indicated that these cells originated from adipose tissues and gingival tissues. In the present study, the surface properties and multidirectional differentiation ability of the AMSCs and GMSCs indicated the characteristics of MSCs. After MSCs were co-cultured with EC-conditioned medium for 5 days, $20.01 \pm 2.06 \%$ AMSCs began to express CD31 protein and $18.85 \pm 1.05 \%$ GMSCs began to express CD31 protein. After MSCs co-culture with ECs for 5 days, 
A
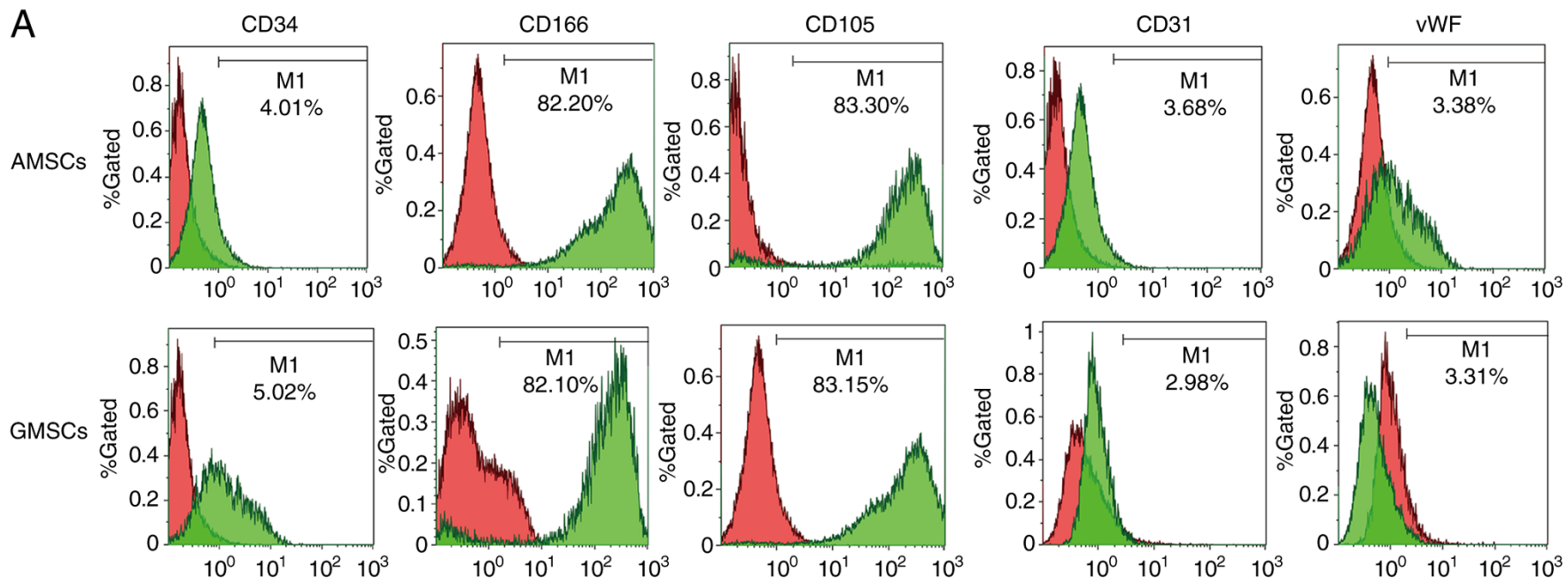
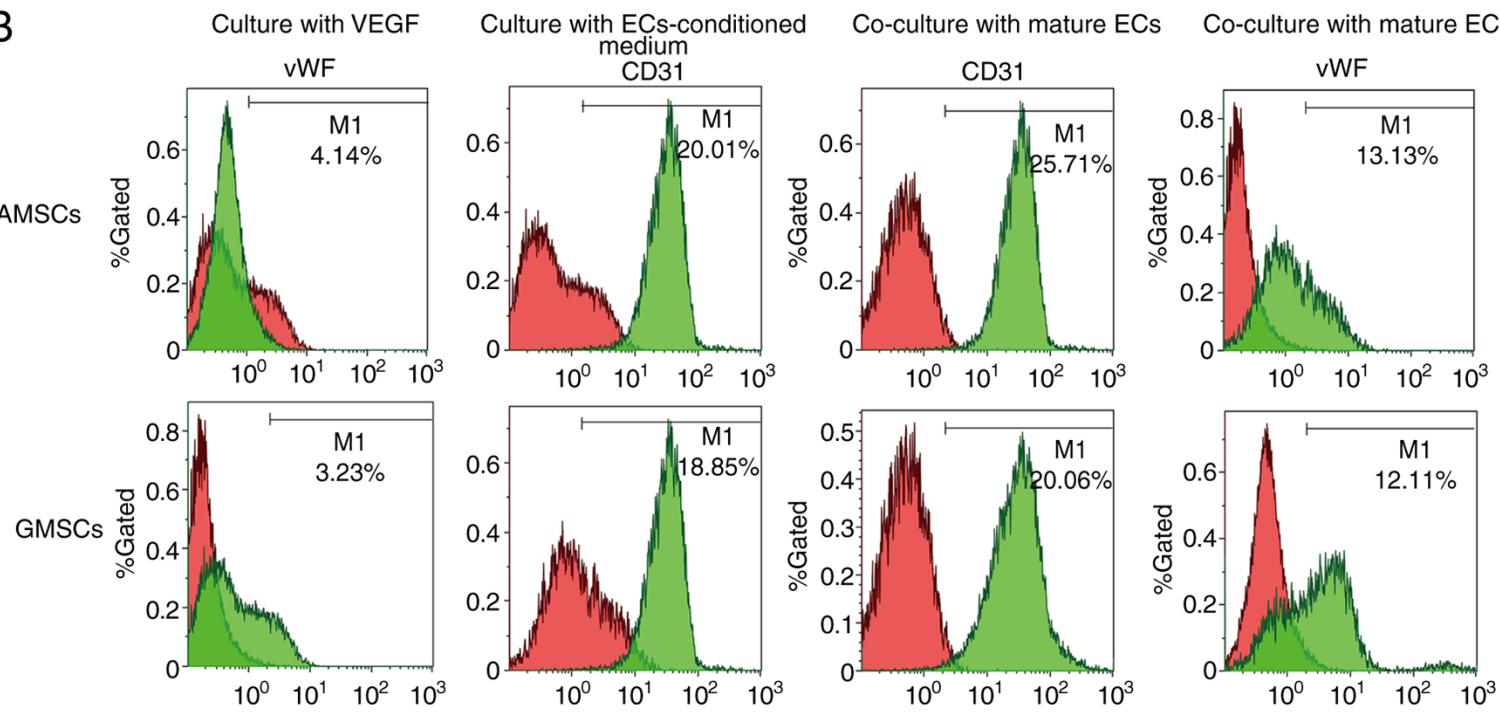

Figure 2. Phenotypic characterization of AMSCs and GMSCs. (A) CD34, CD166, CD105, CD31 and vWF expression levels in the freshly isolated AMSCs and GMSCs. (B) vWF expression of AMSCs and GMSCs after culture with VEGF (50 ng/ml) for 5 days. CD31 expression of AMSCs and GMSCs after culture with ECs-conditioned medium for 5 days. CD31 and vWF expression levels of AMSCs and GMSCs after co-culture with mature rabbit ECs for 5 days. ECs, endothelial cells; MSCs, mesenchymal stem cells; AMSCs, adipose MSCs; GMSCs, gingival MSCs; vWF, von Willebrand factor.

$25.71 \pm 3.08 \%$ AMSCs began to express CD31 protein (Fig. 2B) and $20.06 \pm 2.09 \%$ GMSCs began to express CD31 protein, although they did not express vWF (Fig. 2B).

Detection of multidirectional differentiation ability of AMSCs and GMSCs. AMSCs and GMSCs have the ability to differentiate into osteogenic, adipogenic and chondrogenic lineages, staining positive with Alizarin Red, Oil Red O and Toluidine Blue, respectively. On Oil Red O staining, all orange-red lipid droplets appeared in the form of grape-like clusters. Alizarin Red staining revealed widespread red-positive calcium nodules and toluidine blue staining indicated the widespread formation of chondrocyte lacunae (Fig. 3).

Effect of co-culture with MSCs on SMC proliferation. In order to determine the effect of AMSC and GMSC implantation in the presence of ECs on SMC proliferation, 3H-TdR assays and western blot analysis were used to detect the changes of PCNA protein expression in SMCs. As presented in Fig. 4, compared with the control group, proliferative ECs significantly stimulated the $3 \mathrm{H}-\mathrm{TdR}$ incorporation of SMCs, while confluent ECs inhibited the 3H-TdR incorporation of SMCs $(\mathrm{P}<0.05)$. The $3 \mathrm{H}-\mathrm{TdR}$ incorporation in the co-culture group of AMSCs and SMCs in the presence of ECs was lower compared with that in the proliferative ECs group and the GMSCs and SMCs co-culture groups, but was still higher than that in the confluent ECs group, and the difference was statistically significant $(\mathrm{P}<0.05)$. The results regarding $\mathrm{PCNA}$ protein expression were consistent with those of the 3H-TdR incorporation assay, and it was indicated that, compared with SMCs in the control group, proliferative ECs significantly stimulated the PCNA protein expression of SMCs, while confluent ECs significantly inhibited the PCNA protein expression of SMCs $(\mathrm{P}<0.05)$.

Effect of co-culture of AMSCs and GMSCs on SMC migration. The results demonstrated that in the control group, SMCs spontaneously migrated from the upper chamber of the Transwell to the lower chamber. Compared with the control group, proliferative ECs significantly stimulated SMC 


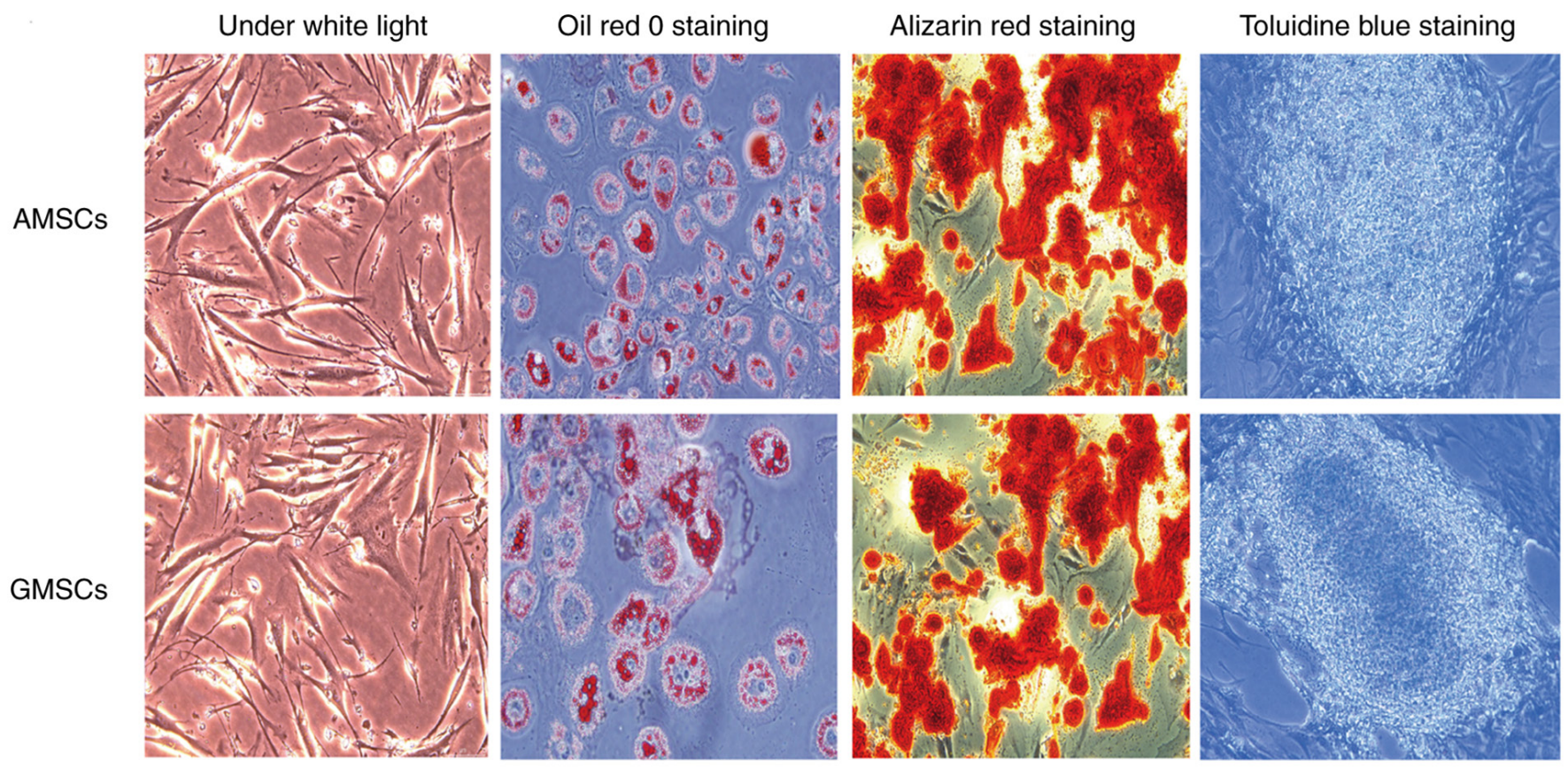

Figure 3. AMSCs and GMSCs have the capacity for adipogenic, osteogenic and chondrogenic differentiation (magnification, x200). MSCs, mesenchymal stem cells; AMSCs, adipose MSCs; GMSCs, gingival MSCs.

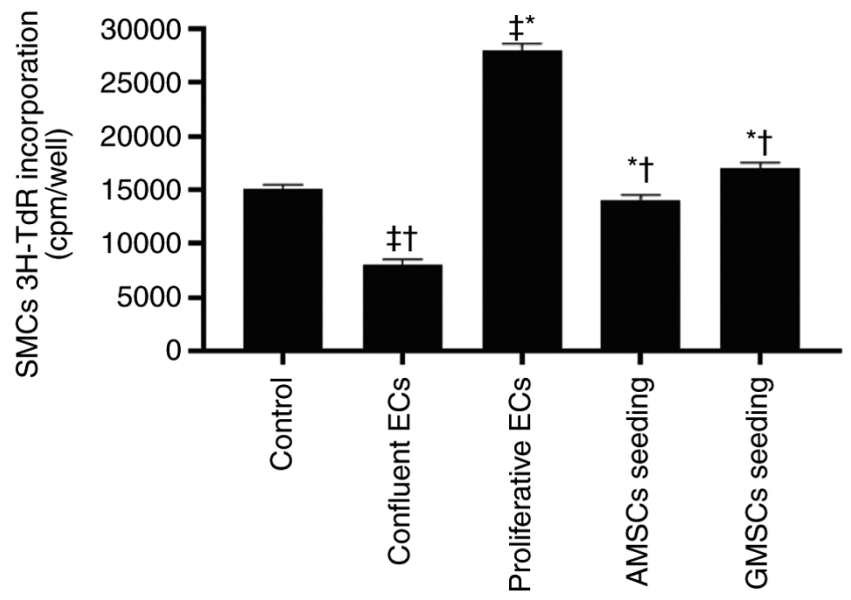

Figure 4. Effect of MSC seeding on top of ECs on 3H-TdR incorporation of SMCs. Values are expressed as the mean \pm standard deviation. ${ }^{*} \mathrm{P}<0.001$ vs. confluent ECs group; ${ }^{\dagger} \mathrm{P}<0.001$ vs. proliferative ECs group; ${ }^{\dagger} \mathrm{P}<0.001$ vs. control group. ECs, endothelial cells; MSCs, mesenchymal stem cells; AMSCs, adipose MSCs; GMSCs, gingival MSCs; SMCs, smooth muscle cells; 3H-TdR, 3H thymine.

migration, while confluent ECs significantly inhibited SMC migration $(\mathrm{P}<0.05$; Fig. 5). The PCNA protein expression level in the co-culture group of AMSCs and SMCs was lower compared with that in the proliferative ECs group and the GMSCs and SMCs co-culture group, but higher than that in the confluent ECs group, and the difference was statistically significant $(\mathrm{P}<0.05$; Fig. 6). These results indicated that confluent ECs significantly inhibited the proliferation and migration of SMCs, while proliferative ECs promoted the proliferation and migration of SMCs. Compared with the control group, co-culture of AMSCs and ECs inhibited the proliferation and migration of SMCs, which was more obvious compared with the proliferative ECs, but not as notable as confluent ECs. Furthermore, co-culture of AMSCs and ECs inhibited the proliferation and migration of SMCs, which was more significant compared with the co-culture of GMSCs and SMCs, and the difference was statistically significant $(\mathrm{P}<0.05)$.

Effect of anti-VEGF antibody on the count of CD31-positive cells after co-culture of AMSCs or GMSCs with ECs. Mature ECs secrete VEGF, and thus, AMSCs and GMSCs were implanted into ECs to determine whether AMSCs and GMSCs are able to differentiate into ECs. This experiment aimed to distinguish whether differentiated MSCs are able to differentiate into ECs and exhibit protein expression characteristics for the phenotype of ECs during co-culture with ECs. The results demonstrated that the newly isolated MSCs did not express CD31 or vWF proteins, but after co-culture with ECs for 5 days, $25.71 \pm 3.08 \%$ AMSCs began to express CD31 protein (Fig. 2B) and 20.06 $\pm 2.09 \%$ GMSCs began to express CD31 protein, although they did not express vWF (Fig. 2B). Under the same conditions of culture in DMEM containing VEGF $(50 \mathrm{ng} / \mathrm{ml})$ for 5 days, AMSCs expressed more vWF protein and the difference was statistically significant $(\mathrm{P}<0.05$; Fig. 7). Under the same conditions of co-culture with ECs, AMSCs expressed more CD31 protein and the difference was statistically significant $(\mathrm{P}<0.05 ;$ Fig. 8$)$. The results indicated that the anti-VEGF antibody was able to inhibit the differentiation of MSCs. The inhibition of CD31 expression in AMSCs and GMSCs was associated with the addition of antibodies and occurred in a dose-dependent manner. The effect observed in AMSCs was more significant compared with that in GMSC, and the difference between the two was statistically significant. This indicated that the differentiation of the two types of MSCs into ECs was associated with VEGF (Fig. 9). 


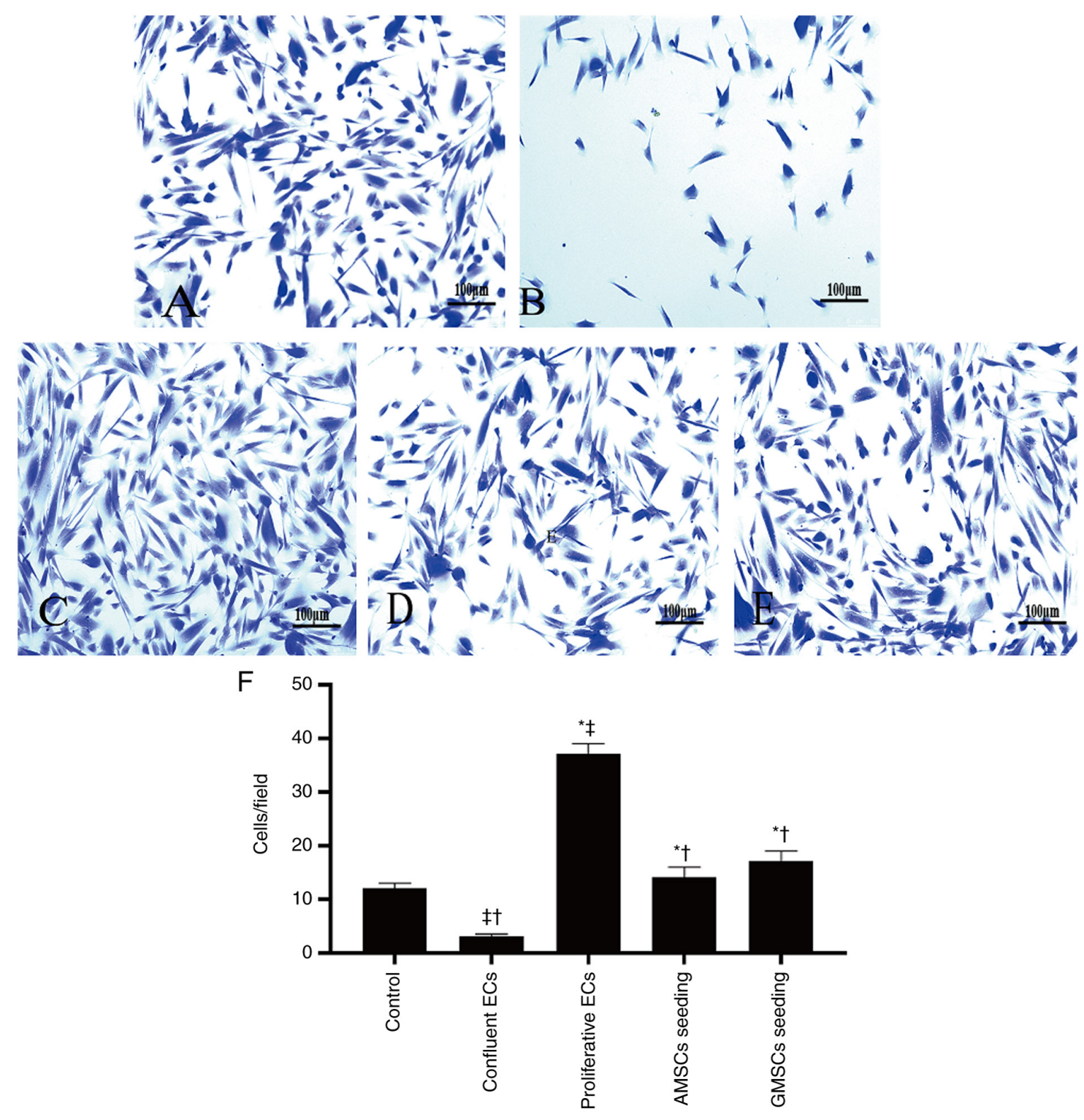

Figure 5. Effect of AMSC and GMSC seeding on SMC migration. (A-E) Each of the images is a representative photomicrograph of SMC migration in the groups evaluated: (A) Control group; (B) confluent ECs group; (C) proliferative ECs group; (D) AMSCs seeding group; and (E) GMSCs seeding group (scale bar, $100 \mu \mathrm{m}$ ). (F) Quantitative results of SMC migration in the different groups. Values are expressed as the mean \pm standard deviation. "P<0.001 vs. confluent ECs group; ${ }^{\dagger} \mathrm{P}<0.001$ vs. proliferative ECs group; ${ }^{\dagger} \mathrm{P}<0.001$ vs. control group. MSCs, mesenchymal stem cells; AMSCs, adipose MSCs; GMSCs, gingival MSCs; ECs, endothelial cells; SMC, smooth muscle cell.

\section{Discussion}

Vascular ECs are the boundary cells between the vascular wall and blood (14). Vascular ECs not only have substance exchange, secretion and barrier functions, but also have important biological anti-inflammatory, antithrombotic and vascular tension regulation effects $(15,16)$. Injury of the endothelium after stent implantation is the initiation point of numerous risk factors (17). The present results suggested that ECs affected the proliferative characteristics of SMCs depending on their growth states. These results indicated that recovery of the integrity and function of the intima as soon as possible after stent implantation is key to the treatment of ISR and advanced thrombosis. Furthermore, it was identified that endothelial regeneration participated in the process of endothelial repair and at the same time affected the proliferation and migration of SMCs. This process produces a series of growth factors and cytokines that cause vascular SMCs (VSMCs) to proliferate in blood vessel walls (18). During this process, VSMCs undergo phenotypic transformation and secrete a large amount of extracellular matrix, causing an increase in intimal thickness, thereby leading to ISR. The degree of repair not only depends on the size of the injury area, but is also easily affected by local non-specific anti-proliferative drugs. However, it has been reported that autologous venous ECs transplantation is able to protect the EC wall of the dislodged artery and reduce the proliferation of the intima (19). The major limitation to repairing injured vasculature is the origin of the cell resource. Endothelial progenitor cells (EPCs) exhibit phenotypes similar to those of hematopoietic cells and ECs, but the nature and origin of EPCs remain controversial $(20,21)$.

It has been revealed that in a specific culture environment, MSCs may convert into ECs with an EC phenotype (22). In the present study, it was determined that $25.71 \pm 3.08 \%$ of AMSCs 
A
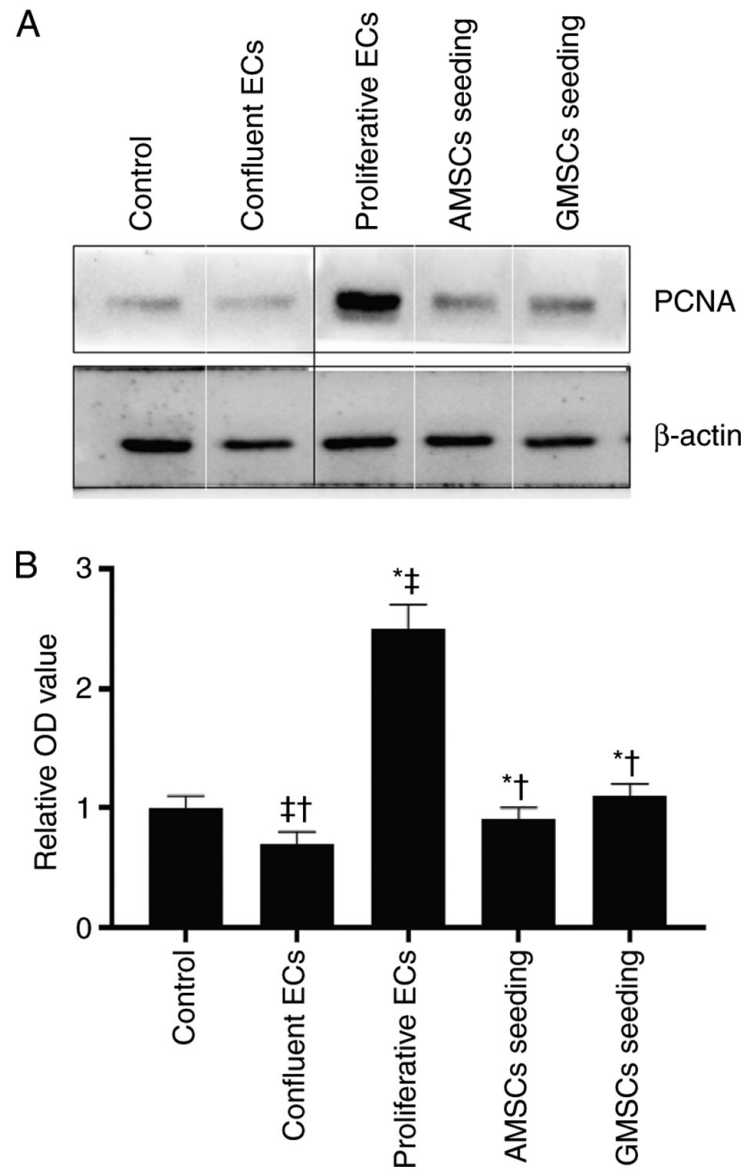

Figure 6. Effect of MSC seeding on PCNA protein expression in SMCs. (A) Representative western blot image and (B) quantitative results. Values are expressed as the mean \pm standard deviation. Composite image showing blots of PCNA protein expression levels in SMCs were tracked from groups of samples analyzed separately, so black lines were used to make the grouping obvious. The boundaries of individual panels of a tiled image were marked using white lines. ${ }^{*} \mathrm{P}<0.001$ vs. confluent ECs group; ${ }^{\dagger} \mathrm{P}<0.001$ vs. proliferative ECs group; ${ }^{\circledR} \mathrm{P}<0.01$ vs. control group. MSCs, mesenchymal stem cells; AMSCs, adipose MSCs; GMSCs, gingival MSCs; ECs, endothelial cells; SMC, smooth muscle cell; PCNA, proliferating cell nuclear antigen.

began to express CD31 protein and 20.06 $22.09 \%$ of GMSCs began to express CD31 protein when they were co-cultured with ECs for 5 days, but these did not express vWF protein. Therefore, MSCs may be used as an alternative to EPCs. In animal models, it was indicated that MSCs were able to inhibit left ventricular remodeling and facilitate myocardial infarction recovery (23). Thus, the present study examined whether AMSC and GMSC seeding is able to inhibit SMC proliferation and migration. The results demonstrated that AMSC seeding inhibited the proliferation and migration of SMCs more strongly than proliferative ECs, but more weakly than confluent ECs. The inhibitive ability of the proliferation and migration of SMCs in the AMSC with ECs group was stronger compared with that in the GMSC co-cultured with ECs group.

Proliferative ECs markedly promoted the proliferation and migration of SMCs, while confluent ECs inhibited the proliferation and migration of SMCs. The ability of MSCs to inhibit SMC proliferation and migration may be associated with the inhibition of EC proliferation. In western blot assay of the present study, the mass of protein loaded per lane was $30 \mu \mathrm{g}$, which overloaded the bands. This was a limitation of the current
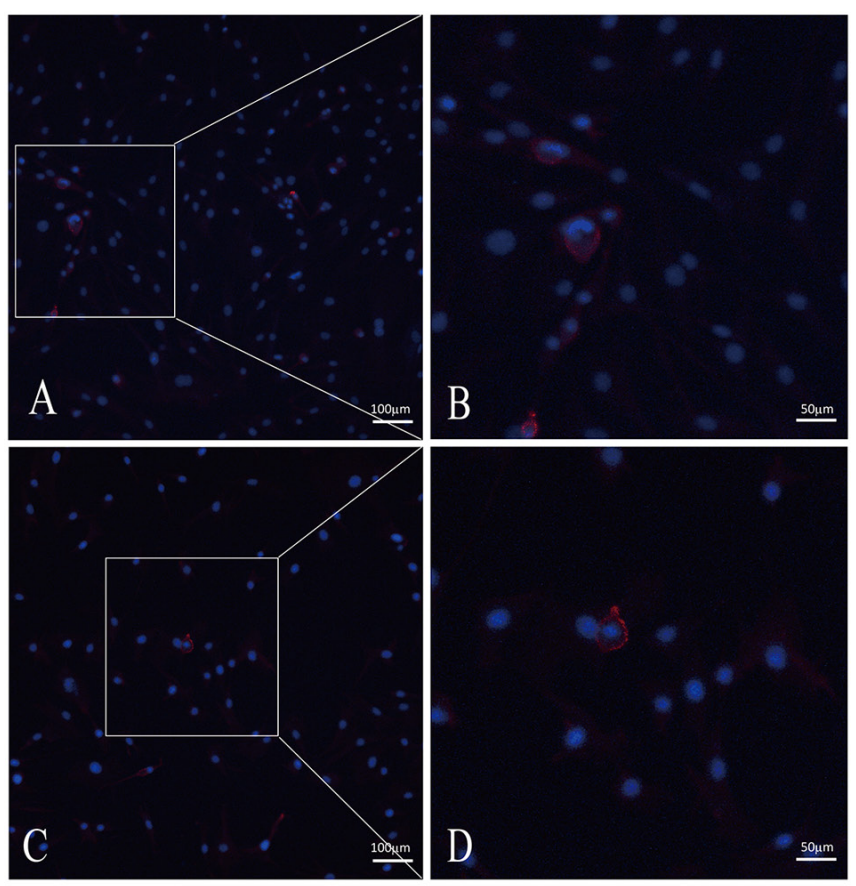

$\mathrm{E}$

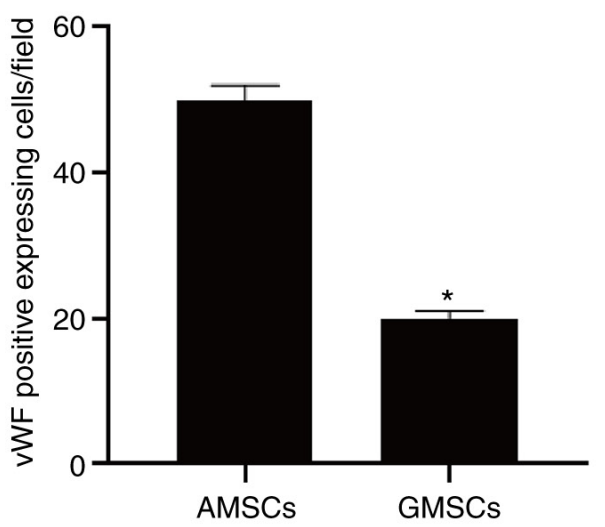

Figure 7. vWF protein expression of the differentiating MSCs. (A) Certain AMSCs began to express vWF protein after culture in DMEM containing VEGF (50 ng/ml) for 5 days (magnification, x100; scale bar, $100 \mu \mathrm{m}$ ); (B) magnified window of A (magnification, x200; scale bar, $50 \mu \mathrm{m}$ ). (C) Certain GMSCs began to express vWF protein after culture in DMEM containing VEGF $(50 \mathrm{ng} / \mathrm{ml})$ for 5 days (magnification, x100; scale bar, $100 \mu \mathrm{m}$ ); (D) magnified window of $\mathrm{C}$ (magnification, $\mathrm{x} 200$; scale bar, $50 \mu \mathrm{m})$. Staining for vWF is in red and nuclei are counterstained with DAPI (blue). (E) Quantitative results. Values are presented as the mean \pm standard deviation. "P<0.05 vs. AMSCs. MSCs, mesenchymal stem cells; vWF, von Willebrand factor; AMSCs, adipose MSCs; GMSCs, gingival MSCs.

study. Spees et al (24) used an ex vivo model of epithelial repair and reported that after co-culture of MSCs and epithelial cells, MSCs and ECs were able to fuse. Several studies have also reported that MSCs are able to express phenotype markers similar to those of cells in a local microenvironment by co-culturing them $(25,26)$. Spees et al $(24)$ demonstrated that when human (h)MSCs are cocultured with heat-shocked human small airway epithelial cells, a subset of hMSCs will rapidly differentiate into epithelial-like cells and express proteins of epithelial cells. Duan et al (25) demonstrated that hBMSCs can be induced towards functional retinal pigment epithelial (RPE) cells simply by Transwell-based co-culture with RPE cells. Intracellular pigment granules and numerous 

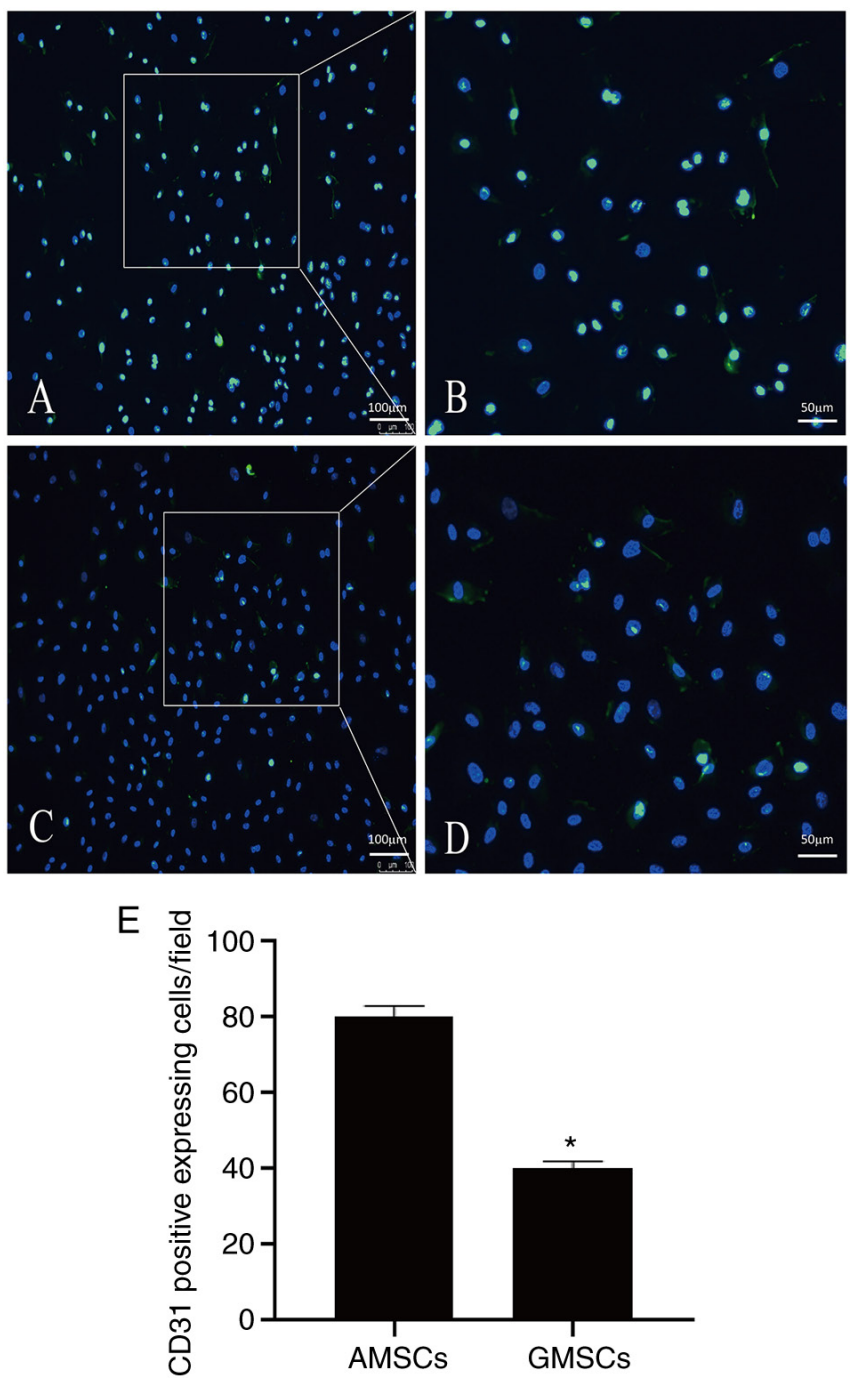

Figure 8. CD31 protein expression of the differentiating MSCs. (A) Certain AMSCs began to express CD31 protein after co-culture with mature ECs for 5 days (magnification, x100; scale bar, $100 \mu \mathrm{m}$ ). (B) magnified window of A (magnification, x200; scale bar, $50 \mu \mathrm{m}$ ). (C) Some of the GMSCs began to express CD31 protein after co-culture with mature ECs for 5 days (magnification, $\mathrm{x} 100$; scale bar, $100 \mu \mathrm{m}$ ). (D) magnified window of $\mathrm{C}$ (magnification, x200; scale bar, $50 \mu \mathrm{m}$ ). Staining for CD31 is in green and nuclei are counterstained with DAPI (dark blue). (E) Quantitative results. Values are presented as the mean \pm standard deviation. ${ }^{*} \mathrm{P}<0.05$ vs. AMSCs. AMSCs, adipose MSCs; GMSCs, gingival MSCs; MSCs, mesenchymal stem cells; ECs, endothelial cells.

RPE markers exist in hBMSCs-derived RPE cells after co-culturing with pig RPE cells for 14 days. Typical RPE functions, such as phagocytosis of photoreceptor outer segments and secretion of the trophic factors, brain-derived neurotrophic factor and glia-derived neurotrophic factor, were observed in these induced cells. Wang et al (26) examined the feasibility of using adipose-derived stem cells (ADSCs) as a source of stem cells for the differentiation of Olfactory ensheathing cells (OECs) by co-culture approach. When co-cultured with OECs, the ADSCs on three-dimensional collagen scaffolds differentiate into OEC-like cells, with similar morphology and antigenic phenotypes (p75NTR $\mathrm{Nestin}^{+} / \mathrm{GFAP}^{-}$) of OECs.

In the present study, it was indicated that both AMSCs and GMSCs co-cultured with ECs expressed markers of endothelial cell phenotypes. In total, 25.71 $\pm 3.08 \%$ AMSCs expressed

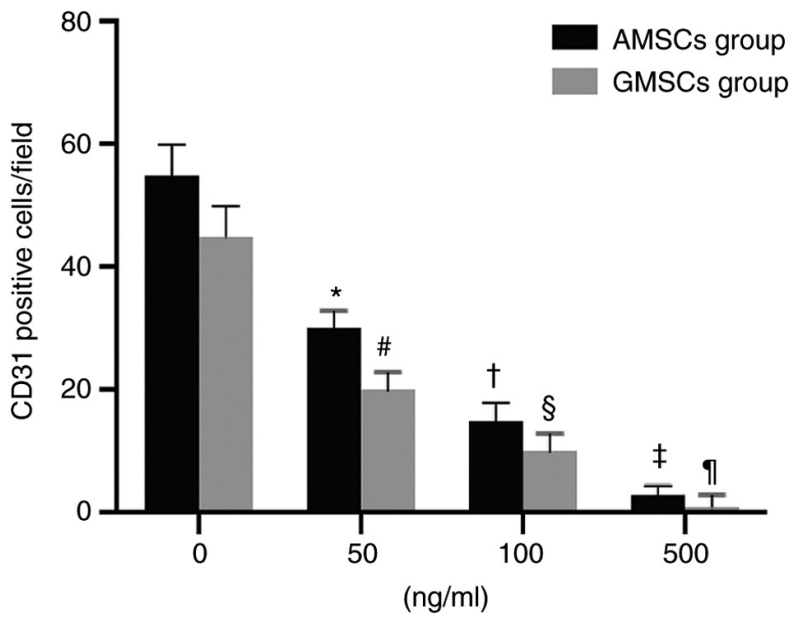

Figure 9. Effect of anti-VEGF antibody on the count of CD31-positive cells after AMSCs and GMSCs were co-cultured with endothelial cells. Values are expressed as the mean \pm standard deviation. ${ }^{* \#} \mathrm{P}<0.01 \mathrm{vs} .0 \mathrm{ng} / \mathrm{ml}$ group;

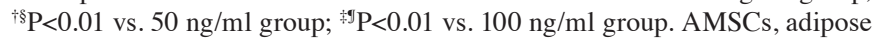
MSCs; GMSCs, gingival MSCs; MSCs, mesenchymal stem cells.

CD31 protein, while $20.06 \pm 2.09 \%$ of GMSCs expressed CD31 protein. However, the MSCs did not express CD31 or vWF protein prior to co-culture with ECs. MSCs are able to differentiate into adipogenic cells, osteogenic cells, cardiomyocytes, smooth muscle and ECs (27). In our preliminary results, it was reported that both AMSCs and GMSCs had the ability to differentiate into adipogenic cells, osteogenic cells, cardiomyocytes and smooth muscle. In the present study, it was identified that both AMSCs and GMSCs had the ability to differentiate into ECs when co-cultured with mature ECs and were in the early stage of differentiation towards the endothelial lineage. Furthermore, anti-VEGF antibodies were able to inhibit the differentiation of MSCs into ECs, indicating that VEGF serves an important role in the differentiation of MSCs into ECs. Anti-VEGF antibodies had a stronger inhibitory effect on the differentiation of GMSCs into ECs than on AMSCs into ECs.

According to previous studies comparing the expression of related genes between AMSCs and GMSCs, it was indicated that the expression levels of chemokines (28), VEGF (29), fibroblast growth factor and insulin-like growth factor, C-X-C motif chemokine receptor 4 and MMP9 (30) were significantly expressed in AMSCs compared with in GMSCs. These factors promote endothelium repair. AMSCs differentiate into ECs through different signaling pathways, such as the ERK signaling pathway or VEGF-A/VEGF receptor 2 (31). Due to the different growth status of ECs, the effect on the biological characteristics of SMCs is also different. Endothelial proliferation itself may stimulate the proliferation and migration of SMCs. It was previously suggested that the STAT3, adenosine monophosphate-activated protein kinase, Akt and Wnt/ $\beta$-catenin signaling pathways, as well as mitochondrial uncoupling, are involved in neointimal hyperplasia (32). In line with this, the present study indicated that the AMSC in co-culture exerted a greater inhibitory effect on SMC migration compared with that of GMSCs as AMSCs secreted a greater variety of cytokines than GMSCs. In accordance with this, AMSCs were reported to inhibit the proliferation and 
migration of SMCs via specific signaling pathways and reduce neointimal hyperplasia (33).

Although MSC transplantation cannot replace mature ECs, this may inhibit SMC proliferation. The key to preventing restenosis and atherosclerosis is to accelerate MSC repair of endothelial damage (34). The mechanisms of MSC differentiation and repair may be further elucidated and cell transplantation therapy may become a novel direction in the treatment of restenosis and atherosclerosis.

In conclusion, the present study demonstrated that both AMSCs and GMSCs had the ability to differentiate into ECs when co-cultured with mature ECs and were in the early stage of differentiation towards the endothelial lineage. Furthermore, AMSC seeding had a stronger effect than GMSCs to inhibit the proliferation and migration of SMCs.

\section{Acknowledgements}

Not applicable.

\section{Funding}

This study was funded by National Natural Fund Surface Project (grant no. 81370214).

\section{Availability of data and materials}

The datasets used and/or analyzed during the current study are available from the corresponding author on reasonable request.

\section{Authors' contributions}

KY was involved in designing the study, writing the protocol and giving final approval of the version to be published. KY analyzed and interpreted data regarding isolation and culture of human AMSCs and GMSCs. DX performed stem cell extraction, acquisition of data regarding multi-differentiation of AMSCs and GMSCs, and was a major contributor in writing the manuscript. DX analyzed and interpreted data of the FACS analysis of AMSCs and GMSCs. WL was involved in drafting the manuscript and analyzed and interpreted data regarding primary culture of ECs and SMCs. PX performed the western blot analysis and participated in data interpretation. CP performed the fluorescence immunocytochemistry and SMC DNA synthesis assays. CP agreed to be accountable for all aspects of the work in ensuring that questions related to the accuracy or integrity of any part of the work are appropriately investigated and resolved. All authors read and approved the final manuscript. KY and $\mathrm{CP}$ confirm the authenticity of all the raw data.

\section{Ethics approval and consent to participate}

The use of clinical specimens for the present study was approved by the hospital's ethics committee and written informed consent was provided by the donors. The Experimental Animal Ethics Committee of The Third Affiliated Hospital of Sun Yat-sen University (Guangzhou, China) approved the animal experimental protocol, which conformed to the principles of animal ethics and the relevant regulations of the national laboratory animal ethics and welfare ethics.

\section{Patient consent for publication}

Not applicable

\section{Competing interests}

The authors declare that they have no competing interests.

\section{References}

1. Bittle GJ, Morales D, Deatrick KB, Parchment N, Saha P, Mishra R, Sharma S, Pietris N, Vasilenko A, Bor C, et al: Stem cell therapy for hypoplastic left heart syndrome: Mechanism, clinical application, and future directions. Circ Res 123: 288-300, 2018.

2. Schizas N, Savvidou O, Triantafyllopoulos I, Papadakis S, Dontas I and Papagelopoulos P: Adjuvant therapies for the enhancement of microfracture technique in cartilage repair. Orthop Rev (Pavia) 11: 7950, 2019

3. Zhou W, Lin J, Zhao K, Jin K, He Q, Hu Y, Feng G, Cai Y, Xia C, Liu $\mathrm{H}$, et al: Single-cell profiles and clinically useful properties of human mesenchymal stem cells of adipose and bone marrow origin. Am J Sports Med 47: 1722-1733, 2019.

4. Mortada I and Mortada R: Epigenetic changes in mesenchymal stem cells differentiation. Eur J Med Genet 61: 114-118, 2018

5. Ding DC, Shyu WC and Lin SZ: Mesenchymal stem cells. Cell Transplant 20: 5-14, 2011.

6. Li T, Xia M, Gao Y, Chen Y and Xu Y: Human umbilical cord mesenchymal stem cells: An overview of their potential in cell-based therapy. Expert Opin Biol Ther 15: 1293-1306, 2015.

7. Cofano F, Boido M, Monticelli M, Zenga F, Ducati A, Vercelli A and Garbossa D: Mesenchymal stem cells for spinal cord injury: Current options, limitations, and future of cell therapy. Int J Mol Sci 20: 2698, 2019.

8. Axel DI, Riessen R, Athanasiadis A, Runge H, Köveker G and Karsch KR: Growth factor expression of human arterial smooth muscle cells and endothelial cells in a transfilter coculture system. J Mol Cell Cardiol 29: 2967-2978, 1997.

9. Yoshida H, Nakamura M, Makita S and Hiramori K: Paracrine effect of human vascular endothelial cells on human vascular smooth muscle cell proliferation: Transmembrane co-culture method. Heart Vessels 11: 229-233, 1996.

10. Clarke LE, Liddelow SA, Chakraborty C, Münch AE, Heiman M and Barres BA: Normal aging induces A1-like astrocyte reactivity. Proc Natl Acad Sci USA 115: E1896-E1905, 2018.

11. Chi Y, Wang D, Wang J, Yu W and Yang J: Long non-coding RNA in the pathogenesis of cancers. Cells 8: 1015, 2019.

12. Vidoni C, Ferraresi A, Secomandi E, Vallino L, Gardin C, Zavan B, Mortellaro C and Isidoro C: Autophagy drives osteogenic differentiation of human gingival mesenchymal stem cells. Cell Commun Signal 17: 98, 2019.

13. Skog S, He Q and Tribukait B: Effect of hyperthermia on thymidine salvage as related to DNA synthesis. Int J Hyperthermia 8: 99-109, 1992.

14. López-Jiménez E, Rojas AM and Andrés-León E: RNA sequencing and prediction tools for circular RNAs analysis. Adv Exp Med Biol 1087: 17-33, 2018.

15. Zhu JJ, Liu YF, Zhang YP, Zhao CR, Yao WJ, Li YS, Wang KC, Huang TS, Pang W, Wang XF, et al: VAMP3 and SNAP23 mediate the disturbed flow-induced endothelial microRNA secretion and smooth muscle hyperplasia. Proc Natl Acad Sci USA 114: 8271-8276, 2017.

16. Minutti CM, Modak RV, Macdonald F, Li F, Smyth DJ, Dorward DA, Blair N, Husovsky C, Muir A, Giampazolias E, et al: A macrophage-pericyte axis directs tissue restoration via amphiregulin-induced transforming growth factor beta activation. Immunity 50: 645-654.e6, 2019.

17. Forslund SK, Kaduk M and Sonnhammer ELL: Evolution of protein domain architectures. Methods Mol Biol 1910: 469-504, 2019.

18. Stahl PD and Raposo G: Extracellular vesicles: Exosomes and microvesicles, integrators of homeostasis. Physiology (Bethesda) 34: 169-177, 2019.

19. Conte MS, VanMeter GA, Akst LM, Clemons T, Kashgarian M and Bender JR: Endothelial cell seeding influences lesion development following arterial injury in the cholesterol-fed rabbit. Cardiovasc Res 53: 502-511,2002. 
20. Ståhl AL, Johansson K, Mossberg M, Kahn R and Karpman D: Exosomes and microvesicles in normal physiology, pathophysiology, and renal diseases. Pediatr Nephrol 34: 11-30, 2019.

21. Zhang D, Zhang G, Li Z and Li B: Activation of the cannabinoid receptor 1 by ACEA suppresses senescence in human primary chondrocytes through sirtl activation. Exp Biol Med (Maywood) 243: 437-443, 2018.

22. Yeh JK, Lin MH and Wang CY: Telomeres as therapeutic targets in heart disease. JACC Basic Transl Sci 4: 855-865, 2019.

23. Deng B, Zhang X, Liang Y, Jiang H, Huang W, Wu Y and Deng W: Nonadherent culture method promotes MSC-mediated vascularization in myocardial infarction via miR-519d/VEGFA pathway. Stem Cell Res Ther 11: 266, 2020.

24. Spees JL, Olson SD, Ylostalo J, Lynch PJ, Smith J, Perry A, Peister A, Wang MY and Prockop DJ: Differentiation, cell fusion, and nuclear fusion during ex vivo repair of epithelium by human adult stem cells from bone marrow stroma. Proc Natl Acad Sci USA 100: 2397-2402, 2003.

25. Duan P, Xu H, Zeng Y, Wang Y and Yin ZQ: Human bone marrow stromal cells can differentiate to a retinal pigment epithelial phenotype when co-cultured with pig retinal pigment epithelium using a transwell system. Cell Physiol Biochem 31: 601-613, 2013.

26. Wang B, Han J, Gao Y, Xiao Z, Chen B, Wang X, Zhao W and Dai J: The differentiation of rat adipose-derived stem cells into OEC-like cells on collagen scaffolds by co-culturing with OECs. Neurosci Lett 421: 191-196, 2007.

27. Yousefnia S, Momenzadeh S, Seyed Forootan F, Ghaedi K and Nasr Esfahani MH: The influence of peroxisome proliferator-activated receptor $\gamma(\mathrm{PPAR} \gamma)$ ligands on cancer cell tumorigenicity. Gene 649: 14-22, 2018.

28. Kimura K, Nagano M, Salazar G, Yamashita T, Tsuboi I, Mishima H, Matsushita S, Sato F, Yamagata K and Ohneda O: The role of CCL5 in the ability of adipose tissue-derived mesenchymal stem cells to support repair of ischemic regions. Stem Cells Dev 23: 488-501, 2014
29. Almalki SG and Agrawal DK: ERK signaling is required for VEGF-A/VEGFR2-induced differentiation of porcine adipose-derived mesenchymal stem cells into endothelial cell. Stem Cell Res Ther 8: 113, 2017.

30. Ratushnyy A, Ezdakova M and Buravkova L: Secretome of senescent adipose-derived mesenchymal stem cells negatively regulates angiogenesis. Int J Mol Sci 21: 1802, 2020.

31. Yang B, Brahmbhatt A, Nieves Torres E, Thielen B, McCall DL Engel S, Bansal A, Pandey MK, Dietz AB, Leof EB, et al: Tracking and therapeutic value of human adipose tissue-derived mesenchymal stem cell transplantation in reducing venous neointimal hyperplasia associated with arteriovenous fistula. Radiology 279: 513-522, 2016.

32. Xiao XL, Hu N, Zhang XZ, Jiang M, Chen C, Ma R, Ma ZG, Gao JL, Xuan XC, Sun ZJ and Dong DL: Niclosamide inhibits vascular smooth muscle cell proliferation and migration and attenuates neointimal hyperplasia in injured rat carotid arteries. Br J Pharmacol 175: 1707-1718, 2018.

33. Takahashi M, Suzuki E, Oba S, Nishimatsu H, Kimura K, Nagano T, Nagai R and Hirata Y: Adipose tissue-derived stem cells inhibit neointimal formation in a paracrine fashion in rat femoral artery. Am J Physiol Heart Circ Physiol 298: H415-H423, 2010.

34. Dzierzak E and Bigas A: Blood development: Hematopoietic stem cell dependence and independence. Cell Stem Cell 22: 639-651, 2018.

(i) $\Theta$ This work is licensed under a Creative Commons Attribution-NonCommercial-NoDerivatives 4.0 International (CC BY-NC-ND 4.0) License. 